\title{
Comparison of Plasma Parameters Between QH and ELMing Phase of the Same Discharges
}

C.J. Lasnier, W.P. West, K.H. Burrell, J.S. deGrassie, E.J. Doyle, T.H. Oborne

This article was submitted to the $16^{\text {th }}$ International Conference on Plasma Surface Interactions

May 2004 


\section{DISCLAIMER}

This document was prepared as an account of work sponsored by an agency of the United States Government. Neither the United States Government nor the University of California nor any of their employees, makes any warranty, express or implied, or assumes any legal liability or responsibility for the accuracy, completeness, or usefulness of any information, apparatus, product, or process disclosed, or represents that its use would not infringe privately owned rights. Reference herein to any specific commercial product, process, or service by trade name, trademark, manufacturer, or otherwise, does not necessarily constitute or imply its endorsement, recommendation, or favoring by the United States Government or the University of California. The views and opinions of authors expressed herein do not necessarily state or reflect those of the United States Government or the University of California, and shall not be used for advertising or product endorsement purposes.

This is a preprint of a paper intended for publication in a journal or proceedings. Since changes may be made before publication, this preprint is made available with the understanding that it will not be cited or reproduced without the permission of the author.

This report has been reproduced directly from the best available copy.

Available to DOE and DOE contractors from the

Office of Scientific and Technical Information

P.O. Box 62, Oak Ridge, TN 37831

Prices available from (423) 576-8401

http: / / apollo.osti.gov/bridge/

Available to the public from the National Technical Information Service

U.S. Department of Commerce 5285 Port Royal Rd., Springfield, VA 22161 http:/ / www.ntis.gov/

OR

Lawrence Livermore National Laboratory Technical Information Department's Digital Library http:/ / www.llnl.gov/tid/Library.html 


\title{
Comparison of plasma parameters between QH and ELMing phases of the same discharges
}

\author{
C.J. Lasnier ${ }^{a^{*}}$, W.P. West ${ }^{b}$, K.H. Burrell ${ }^{b}$, J.S. deGrassie $^{b}$, E.J. Doyle $^{c}$, T.H. Osborne ${ }^{b}$ \\ ${ }^{a}$ Lawrence Livermore National Laboratory, Livermore, California 94550, USA \\ ${ }^{b}$ General Atomics, San Diego, California 92186-5608, USA \\ ${ }^{c}$ University of California, Los Angeles, California 90095-1597 USA
}

\begin{abstract}
H-mode confinement is observed for many energy confinement times without edge localized modes (ELMs) in QH (quiescent high-confinement)-mode discharges in DIII-D [1]. To find critical differences between ELMing and QH modes we compared electron temperature $\left(\mathrm{T}_{\mathrm{e}}\right)$, density $\left(\mathrm{n}_{\mathrm{e}}\right)$, and ion temperature $\left(\mathrm{T}_{\mathrm{i}}\right)$, in the pedestal and scrape-off layer (SOL) for a group of discharges. We also compared the electron pressures $\mathrm{P}_{\text {ped }}$, and maximum pressure gradients $\mathrm{P}_{\mathrm{e}, \mathrm{ped} \text {,max grad }}$ because of their importance in confinement and stability.

Experimental results show that the core line averaged density, median $\mathrm{T}_{\mathrm{e}}$ (pedestal), $\mathrm{SOL}$ $\mathrm{T}_{\mathrm{e}}$, and $\mathrm{T}_{\mathrm{e}}$ pedestal width, and SOL $\mathrm{T}_{\mathrm{i}}$ are nearly the same in $\mathrm{QH}$ mode as that during ELMs. The $\mathrm{n}_{\mathrm{e}}$ (average pedestal), $\mathrm{n}_{\mathrm{e}}$ pedestal width, $\mathrm{P}_{\text {ped, }}$ and $\mathrm{P}_{\mathrm{e}, \mathrm{ped} \text {,max grad }}$ are similar to corresponding values in QH mode and at various times between ELMs. However, the pedestal $\mathrm{T}_{\mathrm{i}}$ is 1.6 times higher in $\mathrm{QH}$ mode than during ELMing.
\end{abstract}

JNM keywords: P0500 Plasma Materials Interaction, P0600 Plasma Properties

PSI-16 keywords: DIII-D, divertor, Edge pedestal, SOL Plasma boundary

PACS: $52.40 . \mathrm{H}, 52.55$

*Corresponding author address: L-637, LLNL, P.O. Box 808, Livermore, CA 94551, USA 
*Corresponding author e-mail: Lasnier@LLNL.gov

Presenting author address: L-637, LLNL, P.O. Box 808, Livermore, CA 94551, USA

Presenting authore-mail: Lasnier@LLNL.gov 


\section{Introduction}

This paper presents a statistical comparison of several important plasma parameters in QH-mode and ELMing H-mode. Quiescent high confinement $(\mathrm{QH})$ mode is exhibited in DIII-D tokamak plasmas with H-mode confinement, long periods with no edge localized modes (ELMs), and constant plasma parameters [1-4]. QH-mode has been seen in ASDEX-U [5], JET [6], and JT60-U [7] and is of interest for avoiding ELM-induced damage to the divertors of future large tokamaks. Observed requirements for $\mathrm{QH}$-mode include neutral beams injected opposite to the plasma current, relatively low plasma density, and a large gap between the outer wall and the plasma separatrix $\left(g_{\text {out }}\right)$. The edge $n_{e}$ and $T_{e}$ profiles in $Q H-$ mode are similar to those of $\mathrm{H}$-mode [8].

We examine time slices from a group of discharges exhibiting both QH and ELMing $\mathrm{H}$-mode behavior, and compare the plasma parameters between the two modes for different times during the ELM cycle. The discharges have been selected with nearly the same toroidal field $(2.0 \pm 0.05 \mathrm{~T})$, plasma current $(1.3 \pm 0.05 \mathrm{MA})$, and upper single-null magnetic configuration. The ion temperature data have been further selected for $9.5 \mathrm{~cm}<\mathrm{g}_{\text {out }}<10.5 \mathrm{~cm}$.

\section{Procedure}

Nearly all the QH discharges exhibit ELMing H-mode at some time during the pulse, often shortly after the neutral beam counter-injection begins. ELMing was often followed by a transition to quiescent behavior at the same confinement and nearly the same density. The plasma parameters analyzed include: electron pedestal temperature $\left(\mathrm{T}_{\mathrm{e}, \mathrm{ped}}\right)$ and density $\left(\mathrm{n}_{\mathrm{e}, \mathrm{ped}}\right)$, $\mathrm{T}_{\mathrm{e}}$ and $\mathrm{n}_{\mathrm{e}}$ pedestal width, maximum electron pressure gradient $\left(\mathrm{P}_{\mathrm{e}, \mathrm{ped} \text {,max grad }}\right)$, electron pedestal pressure $\left(\mathrm{P}_{\mathrm{e}, \text { ped }}\right)$, scrape-off layer $(\mathrm{SOL}) \mathrm{T}_{\mathrm{e}}$ and $\mathrm{n}_{\mathrm{e}}$, pedestal ion temperature $\left(\mathrm{T}_{\mathrm{i}, \mathrm{ped}}\right)$, and SOL $\mathrm{T}_{\mathrm{i}}$. Far SOL values from the modified hyperbolic tangent fit were used for the electron SOL temperature and density. The ion temperatures were obtained from charge- 
exchange recombination spectra of carbon. Electron temperature and density profiles were obtained using modified hyberbolic tangent fits to Thomson scattering data [9]. The SOL value used was from the far SOL part of this fit. Electron pressure was calculated from the product of the electron density and temperature. The maximum electron pressure gradient was from the analytic derivative of the modified hyperbolic tangent.

The QH-mode data were treated as a single group, and statistics of the plasma parameters were obtained. The ELM electron data were separated into groups by ELM phase and the statistics for each phase were determined. The ELM phase is defined as the time since the last ELM divided by the time between the last ELM and next ELM peak in $\mathrm{D}_{\alpha}$, as measured at the outer midplane. For these discharges, the time resolution of the ion temperature data is not sufficient to separate it by ELM phase, so $T_{i}$ is considered in one group averaged over ELM phase.

In the figures, square symbols represent the median value of a quantity during ELMing at a particular ELM phase, circles are the average value, and a band depicts the median QH value. The height of the band represents the error bar. Some of the figures use a suppressed zero to better illustrate small variations. The size of all error bars is $\square / \sqrt{n}$ where $/ /$ is the standard deviation of the sampled quantity and $n$ is the number of samples.

\section{Results}

\section{A. Electron temperature}

Immediately after an ELM, the pedestal $\mathrm{T}_{\mathrm{e}}$ drops $10 \%-15 \%$ and then recovers its preELM value before the next ELM. The QH-mode pedestal median electron temperature is slightly (2\%) higher than in any part of the ELMing phase [Fig. 1(a)].

The electron temperature in the SOL shows a 25\% drop after an ELM pulse, nearly twice the change in the pedestal. The $\mathrm{QH}$ value is nearly the same as the highest inter-ELM value 
[Fig. 1(b)]. The median $\mathrm{T}_{\mathrm{e}}$ pedestal width is essentially unchanged during the ELM cycle (but the mean $\mathrm{T}_{\mathrm{e}}$ pedestal width rises), and is the same in the QH and ELMing phases [Fig. 1(c)].

\section{B. Electron density}

The median electron pedestal density $\left(\mathrm{n}_{\mathrm{e}, \mathrm{ped}}\right)$ increases abruptly, then more gradually, after an ELM, until the next ELM, when it drops quickly [Fig. 2(a)]. In this data set the highest value of $n_{e, p e d}$ is $35 \%$ more than the lowest $n_{e, p e d}$. The $\mathrm{QH}$ value of $n_{e, p e d}$ is nearly the same as the lowest value during ELMing, which occurs shortly after the ELM (ELM phase 5\%).

The SOL density drops at the time of an ELM pulse, then rises sharply to a plateau, which is held until the next ELM. The QH SOL density corresponds to the plateau level during ELMing [Fig. 2(b)].

The width of the electron density pedestal is largest immediately after an ELM, then decreases a factor of two, reaching a plateau value until the next ELM. The width during QHmode corresponds to the plateau level during ELMing [Fig. 2(c)].

\section{Ion temperature}

The median pedestal $\mathrm{T}_{\mathrm{i}}$ is much higher in QH-mode than during ELMing (Fig. 3), by a factor of 1.6, even though similar densities, input power levels, and energy confinement occur in the two phases.

The SOL $\mathrm{T}_{\mathrm{i}}$ is similar in QH-mode to that during ELMing (Fig. 4).

\section{Electron pressure in the pedestal}

The median electron pressure $\mathrm{P}_{\mathrm{e} \text {,ped }}$ at the top of the pedestal [Fig. 5(a)] drops by $\sim 40 \%$ shortly after an ELM, and recovers before the next ELM. The QH value of $\mathrm{P}_{\mathrm{e}, \mathrm{ped}}$ is intermediate between these extremes. This supports the idea that in QH-mode the ELM is 
replaced by another mode, usually the continuous edge harmonic oscillation (EHO) which appears to regulate the pedestal particle confinement and pedestal pressure.

The maximum electron pressure gradient in the pedestal $\mathrm{P}_{\mathrm{e}, \mathrm{ped}}$ max grad shows a dramatic change over an ELM cycle. The ELMing $\mathrm{P}_{\mathrm{e}, \mathrm{ped} \text { max grad }}$ is $30 \%$ less steep than the QH -mode gradient immediately after an ELM pulse, steepens to the QH value at 15\% ELM phase, then at later ELM phase reaches $40 \%$ steeper than the QH gradient. Clearly the

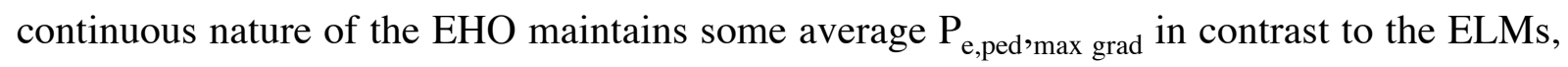
probably due to the EHO ejecting particles from the plasma.

\section{Discussion}

Each of the averaged parameters examined for the ELMing H-modes attains a similar value to QH-mode values at some particular ELM phase, although the precise timing differs for each parameter. The exception is $T_{i}$ in the pedestal, which is consistently higher during QH-mode.

The $\mathrm{T}_{\mathrm{e} \text {,ped }}$, SOL $\mathrm{T}_{\mathrm{e}}$, and $\mathrm{T}_{\mathrm{e}}$ pedestal width, do not show a large difference from a constant ELM value in this data, within limits of the error bars. The value of $n_{e, p e d}$ for QH-mode matches ELMing $\mathrm{H}$-mode at an ELM phase of 5\% and clearly does not match later ELM phases. The SOL $n_{e}$ for QH-mode is close to ELMing $n_{e}$ for ELM phase $\geqq 20 \%$. The width of the $\mathrm{n}_{\mathrm{e}}$ pedestal for QH-mode agrees with the ELMing value for ELM phases $\geqq 45 \%$. Both the $\mathrm{P}_{\mathrm{e}, \mathrm{ped}}$ and $\mathrm{P}_{\mathrm{e}, \text { ped }}$ max grad for QH-mode agree with ELMing H-mode for an ELM phase of 15\%. The $\mathrm{T}_{\mathrm{i}, \mathrm{ped}}$ values for QH-mode are 1.6 times the respective values in ELMing H-mode.

The tempting conclusion is that the higher ion temperatures are responsible for producing QH-mode, although uncertainties in the data may not justify this, nor is this a complete examination of the plasma behavior. However, our results do place a constraint on any model 
seeking to explain QH-mode. Database work can be a useful guide, but does not take the place of detailed experimental comparisons. Within this set of discharges are a variety of plasma shapes, heating power, momentum input, edge current (not measured in this data set), and other variables. All have effects on the pedestal stability limit and transport. Nevertheless, the data in this paper indicate that $\mathrm{QH}$ mode parameters remain within the range of time variation for ELMs except for $\mathrm{T}_{\mathrm{i}}$. Possibly the difference in ion temperatures is caused by fast ions in QH mode, which may play a role in stabilizing the ELMs.

\section{Acknowledgment}

This work was supported by the U.S. Department of Energy under W-7405-ENG-48, DEFC02-04ER54698 and DE-FG03-01ER54615.

This work was done in part under the auspices of the U.S. Department of Energy by the University of California, Lawrence Livermore National Laboratory under Contract No. W-7405-Eng-48. 


\section{References}

[1] K.H. Burrell, et al., Phys. Plasmas 8 (2001) 2153.

[2] C.M. Greenfield, et al., Phys. Rev. Lett. 86 (2001) 4544.

[3] W.P. West, et al., Phys. Plasmas 9 (2002) 1970.

[4] W.P. West, K.H. Burrell, and J.S. deGrassie "Quiescent H-mode, an ELM-free HighConfinement Mode on DIII-D with Potential for Stationary State Operation," Proc. 30th Euro. Conf. on Control. Fusion and Plasma Physics, St. Petersburg, Russian Federation, 2003 (European Physical Society, Geneva) CD-ROM.

[5] W. Suttrop, , et al., Plasma Phys. Control. Fusion 45 (2003) 1399.

[6] W. Suttrop private communication (2003).

[7] Y. Sakamoto, private communication (2003).

[8] W.P. West, et al., Plasma Phys. Control. Fusion 46 (2004) A179.

[9] R.J. Groebner and T.H. Osborne, Phys. Plasmas 5 (1998) 1800. 


\section{Captions}

Fig. 1. (a) $\mathrm{T}_{\mathrm{e} \text {,ped }}$ vs ELM phase, (b) SOL $\mathrm{T}_{\mathrm{e}}$ vs ELM phase, (c) $\mathrm{T}_{\mathrm{e}}$ pedestal width vs ELM phase. In this and succeeding figures, square symbols represent median values during ELMing, circles denote average values during ELMing, and the band represents the value during QH mode.

Fig. 2. (a) $n_{e, p e d}$ vs ELM phase, (b) SOL $n_{e}$ vs ELM phase, c) $n_{e}$ width vs ELM phase.

Fig. 3. ( a) Histogram of $\mathrm{T}_{\mathrm{i}, \mathrm{ped}}$ during $\mathrm{QH}-$ mode, (b) for ELMing.

Fig. 4. (a) Histogram of SOL $\mathrm{T}_{\mathrm{i}}$ during QH-mode, (b) for ELMing.

Fig. 5. (a) $\mathrm{P}_{\mathrm{e} \text {,ped }}$ vs ELM phase (b) Maximum gradient of $\mathrm{P}_{\mathrm{e}, \mathrm{ped}}$ vs ELM phase. 


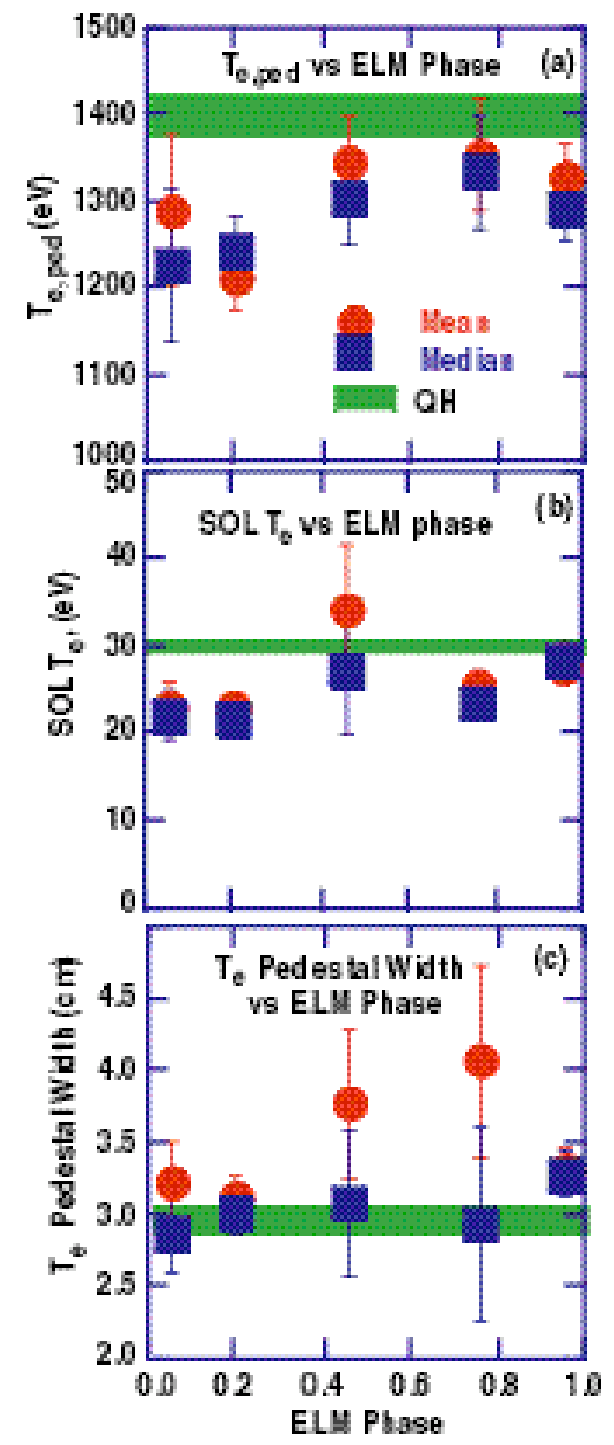

C.d. Lasnier Figure 1 


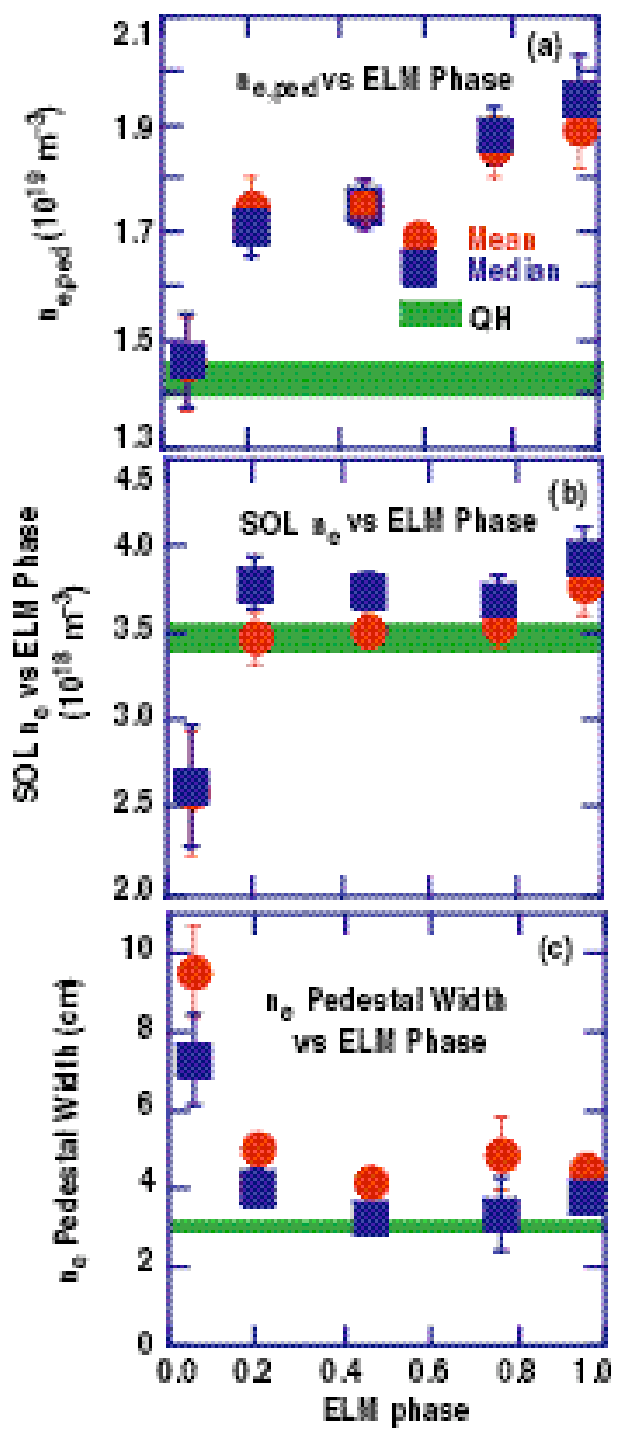

C.J. Lasnier Figure 2 

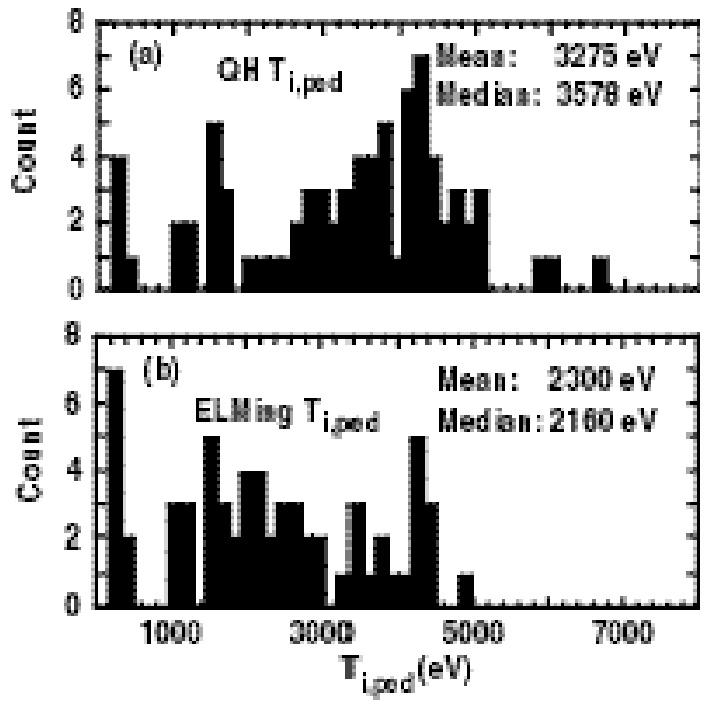

C.d. Lasnier Figure 3 


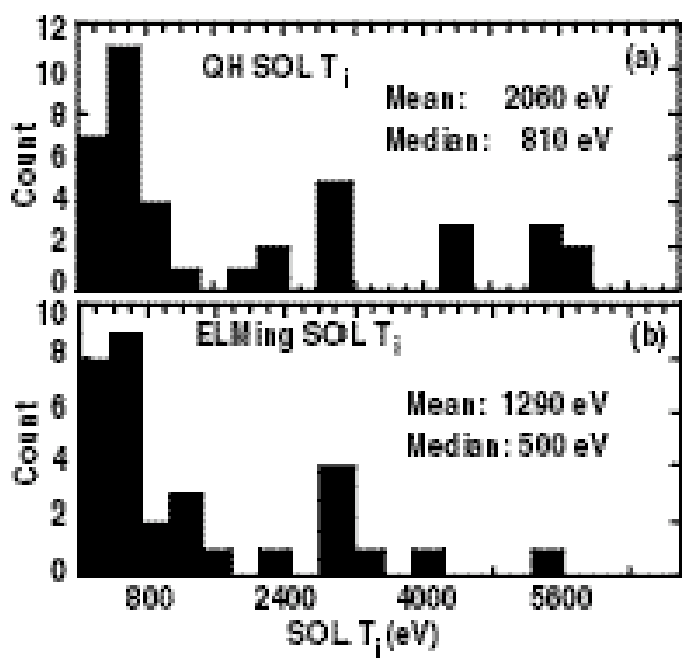

C.d. Lasnier Figure 4 


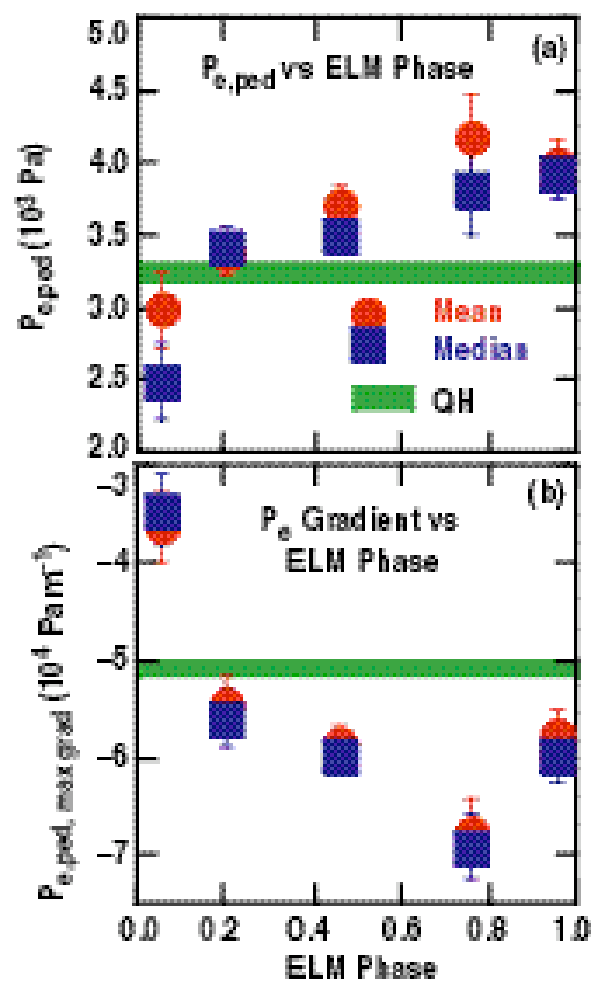

C.d. Lanier Figure 5 
Univverilty of California

Lawrence Livermere National Laboratery

Technical Information Department

Livermore, CA 94551

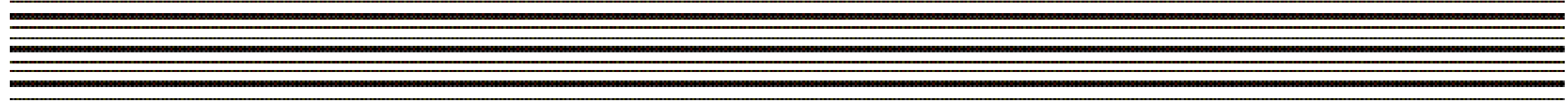

